\title{
The pilot project "Patterns and processes of the ecosystems of the northern Mid-Atlantic": aims, strategy and status
}

\section{Le projet-pilote «Organisation et processus des écosystèmes du moyen Atlantique Nord » : objectifs, stratégie et état d'avancement}

\author{
Odd Aksel Bergstad ${ }^{\mathrm{a}, *}$, Olav Rune God $\emptyset^{\mathrm{b}}$ \\ anstitute of Marine Research, Flødevigen Marine Research Station, 4817, His, Norway \\ bInstitute of Marine Research, P.O. Box 1870 Nordnes, 5817, Bergen, Norway
}

\begin{abstract}
The Mid-Atlantic Ridge is the target of an emerging international ecosystem study under the Census of marine life programme. This pilot project shall gather new knowledge on biodiversity, distribution patterns, and ecological processes, and the overriding aim is "to describe and understand the patterns of distribution, abundance and trophic relationships of the organisms inhabiting the mid-oceanic North Atlantic, and identify and model ecological processes that cause variability in these patterns". The project will focus on pelagic, benthopelagic and epibenthic macrofauna, and analyse distribution and abundance patterns in relation to the abiotic and biotic environment, as well as trophic relationships and life history strategies. Fish, crustaceans, cephalopods and gelatinous plankton and nekton have the highest priority in the study. A major challenge of the project is to overcome observation difficulties at large depths and in rugged terrain. A central aim is thus to utilise modern remote sensing technology (acoustics, optics) using advanced instrument carriers (e.g. towed vehicles, ROVs, AUVs, etc.). The project will be carried out as a multi-ship operation in 2003-2005, and the ongoing planning is a collaborative effort involving many nations around the North Atlantic. The project will work on the Mid-Atlantic Ridge and in adjacent waters from the Azores to Iceland, both by surveying large areas by acoustics and mid-water trawling, and by focusing on three selected sub-areas for intensive sampling and observation by traditional and novel methods and technology. Overlapping with the field seasons, the period 2004-2008 will be an analytical phase, also including submission of data to OBIS.
\end{abstract}

(C) 2002 Ifremer/CNRS/IRD/Éditions scientifiques et médicales Elsevier SAS. All rights reserved.

\section{Résumé}

La ride médio-atlantique est la cible d'une étude internationale naissante de son écosystème, dans le cadre du programme de Recensement de la vie marine. Ce projet-pilote doit rassembler les connaissances nouvelles sur la biodiversité, la distribution et les processus écologiques. L'objectif assigné est de « décrire et comprendre les types de distribution, l'abondance et les relations trophiques des organismes vivant dans la partie centrale de l'Atlantique Nord, d'identifier et de modéliser les mécanismes écologiques qui régulent la variabilité de cette organisation ». Ce programme, centré sur la macrofaune pélagique, benthopélagique et épibenthique, doit analyser la distribution et l'abondance en relation avec l'environnement biotique et abiotique aussi bien que les relations trophiques et les différentes stratégies dans les cycles de vie. Les études portant sur les poissons, les crustacés, les céphalopodes, le plancton fragile et le necton sont prioritaires. Un des défis majeurs que ce programme doit relever est de dépasser les difficultés de l'observation en grande profondeur et en terrain accidenté. Un point-clef est donc de s'appuyer sur les techniques modernes de télédétection (acoustiques et optiques) utilisant les véhicules récents (par exemple des véhicules remorqués, des ROV, des AUV, etc.). Ce projet s'appuiera sur une opération à plusieurs navires en 2003-2005 impliquant un effort coopératif de nombreux pays du pourtour de l'Atlantique Nord. La zone d'étude est la ride médio-atlantique et les eaux adjacentes, des Açores à l'Islande ; elle sera étudiée aussi bien à grande échelle par les techniques acoustiques et le chalutage semi-pélagique que par des études fines sur trois zones-clefs avec un échantillonnage intensif et une observation s'appuyant sur les techniques classiques et modernes. Débordant sur ces campagnes de terrain, la période 2004-2008 constituera la phase d'analyse comprenant la soumission des données à la base Obis.

(C) 2002 Ifremer/CNRS/IRD/Éditions scientifiques et médicales Elsevier SAS. Tous droits réservés.

Keywords: Mid-Atlantic; Ridge; Macrofauna; Biodiversity

Mots clés: Médio-atlantique; Ride; Macrofaune; Biodiversité

\footnotetext{
* Corresponding author.

E-mail address: oddaksel@imr.no (O.A. Bergstad).
} 


\section{Introduction}

When selecting targets for pilot projects under the Census of marine life (CoML), great effort is focused on poorly known ecosystems and communities for which new information would be particularly important to enhance understanding or model formulations (e.g. Ausubel, 1999). The oceanic areas off the continental shelves and the communities of mid-oceanic ridges and the mesopelagic zone represent such target systems. This is even the case in the North Atlantic where, compared with most other waters, the research effort has been extensive for more than a century.

Despite the wide distribution and extensive area of mid-ocean ridges (Fig. 1, Garrison, 1993), relatively few previous investigations have been dedicated to the study of the animal communities inhabiting these vast areas of the world ocean. Ridges may have characteristic faunas, but they may also significantly influence the processes affecting the slope and shelf biota such as intercontinental migration and dispersion. Based on this background, and on the basis of previous experience from extensive ecosystem programmes in the Barents Sea and the Norwegian Sea as well as from intensive fishery-related research activities in home waters and internationally, Norway has offered to take the lead in developing a regional collaborative pilot project focusing on macrofauna of the northern Mid-Atlantic Ridge from Iceland to the Azores. In a concept paper entitled "Patterns and processes of the ecosystems of the northern Mid-Atlantic", submitted to the Scientific steering committee (SSC) of the CoML in February 2000, Bergstad (2000) outlined the goals and phases of such a pilot project. The overriding aims of the proposed study in the oceanic North Atlantic were similar to those proposed by the Monterey workshop (Bradley, 1999) as general goals of the global Census, i.e. to address the following questions: What is the biomass of the marine biota, especially higher trophic levels, on a regional scale? How is this biomass distributed spatially, by size, and by taxon? How are these distributions maintained and changed? The idea was to attract partners from many countries surrounding the study area, and thereby draw on the region's best available technological and scientific expertise. This collaborative effort would

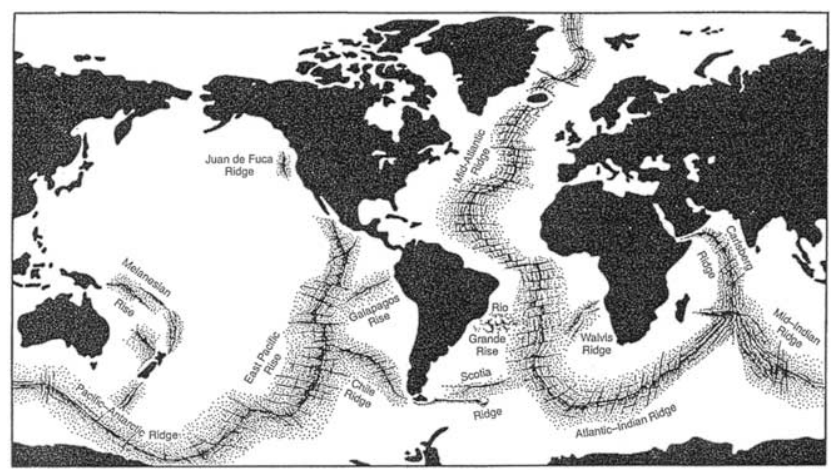

Fig. 1. The ocean ridge system (after Garrison, 1993). provide the opportunity for technological innovation, scientific discovery and greater understanding of the mid-ocean ecosystem.

The SSC of CoML expressed positive interest in this idea and proposed that a regional workshop be organised with the objective of further developing this idea into a pilot project of the Census. The workshop should bring together prospective participants from the region, and the main outcome of the workshop should be a draft science plan for the pilot project suggested. A Norwegian steering committee was formed, and a workshop was convened in Bergen on 12-13 February 2001 (see summary on www.mar-eco.no). Some 35 experts from a wide range of fields and countries were invited to the meeting, and the response was very positive.

The outcome of the Bergen workshop was that an international steering group was set up to carry the process further, i.e. to finalise a draft science plan and to write a proposal for the planning phase of the project. In the early summer of 2001, this group submitted a planning phase proposal to CoML which, following approval and minor revision, was passed on as a formal grant application to the Alfred P. Sloan Foundation. In October 2001, a generous grant was awarded, and the 18-month planning phase of the project, now acronymed Mar-Eco, was initiated. In this paper, an overview of aims, strategies, methods, planning phase tasks, and the current status of Mar-Eco is presented.

The Mar-Eco vision is that, following the 2001-2008 project period, the identity, distribution patterns, food webs, and life history patterns of the macrofaunal communities of the northern Mid-Atlantic Ridge and its flanks will be understood and well known both to the scientific community and the interested public.

\section{Previous studies}

In terms of surface area, the ridge habitats are vast compared with the continental shelf and slope habitats where most of the biological research effort has been focused thus far. Hitherto, many deep-sea biologists have avoided ridge areas because of the cost of surveys and difficulties in using existing sampling equipment that would be readily damaged or lost. The exception is the exploration of chemosynthetic ecosystems, e.g. hydrothermal vents which have attracted considerable research effort (e.g. Van Dover, 2000; see also the InterRidge home page http://triton.ori.u-tokyo.ac.jp/ intridge/). A number of expeditions have been devoted to such systems around the world, but very few on the northern part of the Mid-Atlantic Ridge. Vent fields represent, however, a very minor fraction of the ridge area and the influence of chemosynthetic production on the overall biological production along the ridges is probably small.

The rugged ridge terrain makes any sampling near the sea floor a difficult task, and thus the information on commu- 
nities inhabiting different depth zones and habitats remains relatively limited. Sampling the pelagic environment has been more extensive, but the need to sample large areas and extensive depth ranges makes pelagic studies very expensive and time-consuming.

The deep-water fauna depends ultimately on the rather seasonal photosynthetic production in the surface layers. The annual primary productivity in oceanic waters of the North Atlantic is around $45 \mathrm{~g} \mathrm{C} \mathrm{m}^{-2}$ in the south and $90 \mathrm{~g} \mathrm{C} \mathrm{m}^{-2}$ in the north, and as much as $125 \mathrm{~g} \mathrm{C} \mathrm{m}^{-2}$ southwest of Iceland (Berger, 1989). There are at least two processes by which material can be transferred to deeper layers, i.e. by sinking of aggregates ("marine snow") and the carcasses of large pelagic animals, and by the diurnal migration of large herbivores and carnivores (Angel, 1997). The biomass of nekton and plankton declines systematically with depth, but the number of species rises to a maximum at about $1000 \mathrm{~m}$ and thereafter declines. The traditional classification of the pelagic fauna into epipelagic, mesopelagic, bathypelagic, abyssopelagic and benthopelagic communities is generally accepted. However, along the midocean ridge, the complicated topography and the effects on the circulation system and production of seamounts and the passage of mesoscale eddies may modify the picture significantly. Most previous studies have been conducted either just off the continental slopes or in oceanic basins, and the understanding of the significance and influence of the mid-ocean ridges on the composition and distribution of pelagic and benthic fauna is still limited.

The knowledge of certain very abundant and sometimes very widely distributed taxa such as cephalopods and gelatinous plankton organisms is particularly incomplete. These groups are difficult to sample, and traditionally their significance in pelagic ecosystems has been underrated compared with e.g. fish and crustacean plankton and nekton. In oceanic systems, they are very characteristic (Angel, 1997), and there is evidence that these groups play major roles in the food webs of the ecosystems near the ridges and in frontal zones associated with the major circulation features. The potential for new significant discoveries is particularly great for these groups. But there is also a striking lack of information on more easily sampled zooplankton and micronekton groups such as copepods and euphausids. Most previous studies have only sampled the surface layers, or the deep-sea area to the east of the Mid-Atlantic Ridge.

There is much more information on mid-ocean pelagic fishes, including those inhabiting deeper layers (e.g. Randall and Farrell, 1997; Merrett and Haedrich, 1997). Some of the major 19th and early 20th century expeditions provided significant material and species inventories, and the North Atlantic fish fauna is relatively well known from these and subsequent efforts. But, surprisingly, few previous studies have focused specifically on the role of the mid-oceanic ridges in the ecology of neither demersal nor pelagic fishes.
Considerable knowledge of fishes associated with ridge systems has been gained from fisheries-related research. Pelagic fisheries of the open ocean have been targeting tuna, swordfish, sharks, and redfish that tend to be found near fronts, eddies and islands. Whales also occur in such areas and, like the epipelagic fishes, they carry out extensive migrations. The significance of mid-ocean ridge ecosystems for such long-range migrants is, however, not clear. Traditional demersal fisheries have been conducted on the MidAtlantic Ridge within the Azorean and Icelandic EEZs for many decades. Icelandic data on the distribution of fishes on the Reykjanes Ridge were summarised by Magnusson and Magnusson (1995). USSR fleets started to exploit deepliving species such as alfonsino (Beryx spp.) and roundnose grenadier (Coryphaenoides rupestris) north of the Azores in the 1970s (Troyanovsky and Lisovsky, 1995) and Russian fleets and vessels from other eastern European nations still fish in this area. Many nations have carried out exploratory fishing in the 1990s, e.g. the Faroes (Thomsen, 1998), Norway (Hareide et al., 1993; Langedal and Hareide, 1997), and Spain (Iglesias and Muñoz, 2001). The reported landings from the area remain, however, relatively small and variable, and few vessels find the ridge fisheries profitable. The Russian fisheries appear variable (Vinnichenko, 1998), the Faroese have a single vessel fishing successfully for orange roughy (Hoplostethus atlanticus), Norwegian fisheries on the Reykjanes ridge have almost ceased, and the Spanish are still mainly exploring, focusing strongly on the Hatton bank. Around the Azores, the fisheries are mainly coastal and artisanal, but gradually moving greater distances from the coast and onto seamounts off the islands (Santos et al., 1995).

Fisheries investigations have yielded valuable information on the distribution and abundance of fish, but have mainly considered species of commercial interest. Consequently, the exploratory fishing efforts of the past three decades have only to a very limited degree enhanced our knowledge of the Mid-Atlantic Ridge ecosystems, communities, and the processes that structure and sustain the ridge fauna. Surprisingly, few studies have aimed at providing basic taxonomical or ecological understanding.

Pioneer USSR studies on the Mid-Atlantic Ridge have not been sufficiently known to western scientists, but major research efforts have been reported (e.g. Kukuev et al., 2000 and references therein). See also extensive Russian bibliography on www.mar-eco.no. Comprehensive seamount ecology projects have been carried out in adjacent areas (Hempel, 1968; Hempel and Nellen, 1972; Rogers, 1994; Pfannkuche et al., 2000), and several nations have pursued the challenge of exploring hydrothermal vents (e.g. France, USA, the United Kingdom, Russia, Portugal). Overall, the quantity and quality of the available information on ridge communities and their relation with adjacent basin communities and the slope faunas remain unsatisfactory. New technology and international collaboration make a dedicated effort along the Mid-Atlantic Ridge both feasible, challeng- 
ing and timely, and in view of the global distribution of ridges, such efforts will provide information of great global interest.

In a recent quality status report issued by Ospar (the Oslo-Paris Commission) (Ospar Commission, 2000), a comprehensive review of information on the ecosystems of the oceanic North Atlantic was presented. A number of issues were raised that called for greater research effort in oceanic waters of the North Atlantic, and with regard to biological data, the following list of "uncertainties" was provided:

- basic systematic information about the majority of benthic taxa, especially the smaller organisms;

- the importance of gelatinous organisms in pelagic ecosystems, mainly because they cannot be adequately sampled;

- the role of microorganisms in food webs and many aspects of biogeochemical cycling;

- the zoogeographical patterns and distributions of many keystone species and communities;

- the life cycles of many keystone species;

- the structure and dynamics of most deep-water food webs;

- the biological pathways for contaminants in deep ocean ecosystems;

- the natural variability against which contemporary changes in biological systems can be assessed;

- how long-term cycles in the physical environment affect mid-water and seabed communities and processes;

- the links between biodiversity, productivity and other ecological processes;

- the impact of removing top predators, such as fish, from the oceanic ecosystems; and

- how to distinguish between natural variation and anthropogenically generated change.

Many of these issues raised by Ospar will be addressed by Mar-Eco.

\section{Main aim and tasks of Mar-Eco}

Most previous studies have been short-term and poorly co-ordinated, and the more extensive efforts focused mainly on either fishery development or hydrothermal vent exploration. The limited quantity and scope of documented knowledge of the mid-oceanic ridge macrofauna establishes an essential requirement for new basic and original macrofaunal description to be undertaken. This primary challenge must be met by a co-ordinated programme of species identification and distribution mapping; studies of community composition and individual species behaviour and life history; all set in the context of a full suite of environmental and habitat parameterisation.

The need for a basic exploratory effort formed the basis for the discussion and formulation of the main aim and tasks of Mar-Eco during the Bergen workshop. The overriding agreed objective became "to describe and understand the patterns of distribution, abundance and trophic relationships of the organisms inhabiting the mid-oceanic North Atlantic, and identify and model ecological processes that cause variability in these patterns". It was also decided that the greatest focus should be on mesopelagic and benthopelagic macrofauna (nekton and macrozooplankton), and their trophic relationships. Benthic macrofauna should be described in selected habitats, especially to facilitate analyses of food-web structure involving e.g. benthopelagic and benthic fishes.

The aim is grand and ambitious, especially when considering that the Mid-Atlantic Ridge between Iceland and the Azores extends over 1500 nautical miles and is characterised by a rough bottom topography that has not yet been adequately surveyed.

The Science Plan (available on www.mar-eco.no) presents three central tasks and a compilation of hypotheses and suggestions resulting from discussions during and after the Bergen workshop. The following list of general tasks will remain, but as the planning progresses, changes must be anticipated in the exact formulation of hypotheses and strategies.

Task 1: Mapping of species composition and distribution patterns.

Theme 1: Identity and distribution patterns of macrofauna.

Theme 2: Population genetics and dispersion studies.

Task 2: Identification of trophic interrelationships and modelling of food web patterns.

Task 3: Analyses of life history strategies.

The three tasks are obviously inter-related. Also, all the tasks rely on understanding the abiotic environment. A multi-disciplinary approach will be emphasised to conduct analyses of watermass distributions, advection patterns, detailed topography, and substrate distributions, illumination patterns, etc. It is essential that biologists and physicists work together in a mutually fruitful manner.

Some basic overall hypotheses or questions to be addressed are:

(a) Is the Mar an extension of the North Atlantic basin continental slope regions? Are species occurring at the same depths at which they are found on the continental margins?

(b) Is the Mar a barrier between the pelagic fauna of the east and west North Atlantic basins? Is there a difference in species occurrence either side of the Mar?

(c) Do circulation features, e.g. the North Atlantic Drift, act as barriers between the northern and southern fauna? In the region of the North Atlantic Drift, what is the effect of eastward drift and import of material from the west?

(d) What is the significance of seamounts within the ridge system?

(e) Is the trophic structure of the northern Mid-Atlantic ecosystem similar to that on the slope regions of the eastern and western sides of the Atlantic? 


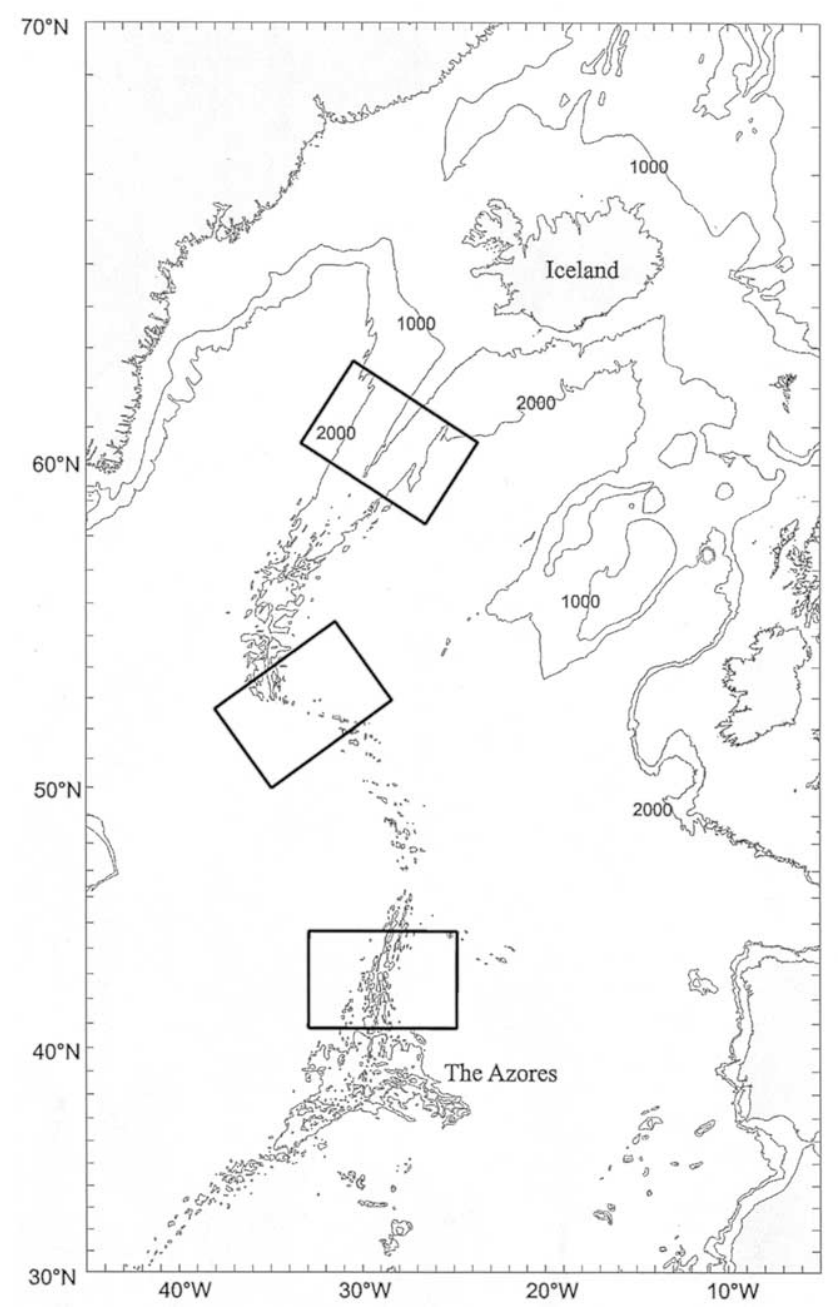

Fig. 2. The three sub-areas selected for detailed Mar-Eco studies. The middle area was moved southwards after discussions during the Bremerhaven workshop in January 2002, hence the location differs from that shown in the Science Plan.

More detailed and complete descriptions of the different task and approaches are given in the Science Plan, and in the proposals for component projects now being formulated.

\section{Strategy and technology}

\subsection{Field campaign}

For the purposes of a species census, two kinds of surveys are proposed:

(a) A large-scale pelagic survey attempting some degree of coverage over the whole area from Iceland to the Azores (Fig. 2).

(b) Focused studies in three areas and along transects accross the axis of the ridge.

A major factor at mid-latitudes is the North Atlantic Drift crossing the ridge from West to East. The flow of water in deeper layers tends to be strongly influenced by topography, and there is flow through the Charlie-Gibbs Fracture zone.
This fracture zone is thus also a hydrographical transition zone between the deep-water to the north and south. Information on the surface circulation and deep flow patterns will influence the final choice of the survey design and the choice of sub-areas for detailed studies. Preliminary criteria for selecting sub-areas were that two comparable sites, i.e. a northern and southern sub-area should allow latitudinal comparisons. In the middle, a third sub-area was placed near the Sub-polar Front usually associated with the Charlie-Gibbs Fracture Zone.

To design a wide-ranging pelagic survey, information on seasonal variation in distribution, abundance and production should be considered and used as the basis for stratification of effort. If biomass is concentrated near the ridge, the survey should include increased short transects over the ridge with wider spaced long transects into the basins. Consideration needs to be given to surveys in different seasons. Satellite data and outputs of models of circulation patterns may provide guidance on the spatial patterns of phytoplankton and surface parameters near the ridge and the sizes and location of patches. Special attention should be given to the location and variability of the North Atlantic Drift.

A range of methods for observation and sampling will be adopted, including trawling, net sampling, acoustics and optics for fish, cephalopods and smaller animals. Cooperation with on-going survey and monitoring programmes will be developed. Multi-frequency acoustic systems will provide data on pelagic scatterers in the more productive upper $1000 \mathrm{~m}$ of the water column. Deep-towed systems, and lower frequencies will be used to provide data on the reduced biomass in deeper water. Pelagic trawling strategies will be based on a regular grid enhanced by opportunistic trawls, aimed at identification of traces observed on the echosounder systems. Abundance will be estimated from swept volume estimates of pelagic fish and cephalopods, where possible, using target strength data. Multi-frequency data should be used to help with species allocation.

Consideration should be given to the use of AUVs to provide intertransect data in the most variable areas. A strategy of short AUV missions over the ridge may provide additional data while a survey vessel is carrying out extended transects into the ocean basins.

Macroplankton distributions should be mapped using multiple opening and closing sampling gears. In addition, high frequency acoustic data should provide broader scale spatial distribution for the upper part of the water column. Special attention should be given to developing good sampling and observation methods for gelatinous plankton.

Application of autonomous towed instrument packages containing similar acoustic and environmental sensors for use on ships in transit through the area will be considered. These data augmented by the main survey should provide some seasonal coverage to put the main survey in the context of the annual cycle in the pelagic community. Fixed 
stations with CTD and bioacoustic packages should be placed at selected sites to provide detailed daily and seasonal data.

There are no adequate fine scale charts of the whole Mar. The possibility of conducting a survey to the study area to provide a basis for planning of the near-bottom sampling programme will be explored. Multibeam charting will be essential, and the observation and sampling shall be carried out with an arsenal of instruments and methods, involving ROVs, baited cameras and landers, traps, longlines, trawls, sledges, grabs etc., and if available, manned submersibles. Fixed stations may again provide very useful data. To obtain adequate sampling with a variety of gears, opportunities for co-operation with commercial fishing vessels will be explored.

Although mammals and seabirds are not primary targets of the project, associated project including sightings and behavioural studies will be a part of the field effort. The limited availability of observation platforms is a major limitation in whale and bird studies in oceanic waters, and Mar-Eco cruises are significant opportunities to collect new information.

\section{Analysis and synthesis}

The substantial amount of data and material collected on surveys and during process studies need to be analysed and processed, and the information will be integrated in at least conceptual models. As the project proceeds, results will be reported and findings disseminated both on its web page, and through press releases. This scientific analysis will take time, and a period of 5 years (2004-2008) has been dedicated to this work. Experts from a wide range of fields will be involved in this process, including scientists not taking part in the field study.

Information collected during the pilot project shall be provided in a format suitable for Obis (Grassle, 2000), and the inclusion of data or linking of databases to OBIS is a central task, in reality, throughout the project period.

The final synthesis will also include the convening of a symposium where the scientific findings from the Mar-Eco project will be presented. Further, the possibility of the publication of the main findings of the project in a popular book will be explored.

\section{The planning phase}

Five inter-related actions will have to be accomplished simultaneously during the planning phase of this project:

Action 1: Project building. Based on current knowledge and ideas (see Action 2), testable hypotheses central to the study of patterns and processes will be developed and refined to tackle the three core tasks defined for the field and analytical phases of this project. These hypotheses will provide greater focus for the pilot project and provide guidance for investigators of the individual tasks. Investigators will have to commit themselves to specific tasks and responsibilities. The writing of component project proposals and acquisition of financial resources are essential activities of the planning phase (see Action 4). Writing of proposals shall be facilitated by networking activity and focused workshops.

Action 2: Literature studies and data mining. Although the mid-ocean ridge system is perhaps the least studied large ecosystem on earth, information pertinent to this project exists. Such information includes results of exploratory fishing on the Mid-Atlantic Ridge, open-ocean studies in the deep Atlantic Ocean, and seamount studies from around the world. Some of this information is in formats that may be difficult to obtain or to interpret. In addition to journal publications, such information includes data and project reports, databases, "grey-literature", and publications in languages that are not widely understood. For example, extensive background information is thought to have resulted from exploratory fishing on the Mid-Atlantic Ridge by former Soviet block nations. Compilation and evaluation of current and archived information will be an important part of the planning process, as well as an important task in the entire project. This research task will therefore begin during the planning phase and continue during the field phase. Early results of this action will be used to refine hypotheses to be tested during the field phase.

Action 3: Technological adaptation and fitting of research vessels. A main aim of the project is to gain new knowledge through the application of new technology. A workshop will be convened to decide on technology and methods to address each task of the field phase. When appropriate, materials and methods will be co-ordinated with other CoML projects so that broader-scale comparisons are optimised (see Action 5). Prior to the main field effort, necessary new technologies should be adapted to and tested in realistic environments. Preliminary cruises by e.g. the Norwegian Institute of Marine Research and the US National Marine Fisheries Service shall serve as platforms for such testing. Purchase of additional equipment and outfitting and scheduling of research vessels for the field phase will be the responsibility of individual investigators and their funding agencies.

Action 4: Promotion of the pilot project and the field activities. Assembling the proposed research, and building support for it will require the establishment of an international communications network. It is important to focus this effort on three co-ordinated sub-tasks: (a) recruiting potential investigators, (b) informing funding agencies, and (c) educating other interested parties, including the general public.

Action 5: Co-ordination. The Steering Committee will co-ordinate sub-projects addressing tasks by working with investigators during proposal development and with funding agencies during the proposal review process. This is to 
ensure that all tasks are addressed but without unnecessary duplication. Members of the Steering Committee will also be designated for liaison with other CoML projects. If relevant similarity among separate CoML projects can be maximised, then broad-scale comparisons (e.g. between the Mar and the slope and seamounts off the Gulf of Maine) will be facilitated. Of particular importance will be co-ordination with Obis to ensure that data from this project can be incorporated directly into that information system.

\section{Organisation and schedule}

\subsection{Steering group and secretariat}

The International Steering Group organises and oversees the planning, financing, and implementation of the pilot project. Members of the group are:

Dr. Odd Aksel Bergstad, IMR, Norway (chair)

Prof. Peter Boyle, Univ. Aberdeen, UK

Dr. Olafur S. Astthorsson, MRI, Iceland

Dr. Ricardo S. Santos, Univ. Azores, Portugal

Dr. Uwe Piatkowski, Univ. Kiel, Germany

Prof. Michael Vecchione, NOAA, NMFS, USA

Dr. E.M. Burreson, Virginia Institute of Marine Science (VIMS)

Prof. Ulf Båmstedt, University of Bergen, Norway

Dr. Pascal Lorance, IFREMER, France

Norway has offered to take on secretarial duties for the project, and the responsible institution will be the Institute of Marine Research (IMR) in collaboration with the University of Bergen. A project secretary and a Public Outreach secretary have been hired for the duration of the planning phase. The forum for the planning process is a project formally embedded in the current activity plan of IMR but open to multi-institutional and international participation. The new $77.5 \mathrm{~m}$ Norwegian research vessel RV G.O. Sars (see http://www.uib.no/gosars/english/) has been committed for 2 months in 2004 and may form a central focus of international multi-vessel operations. Iceland will use its vessel, the RV Arni Fridriksson, for work on the Reykjanes Ridge in 2003.

Collaboration and data sharing with other CoML pilot projects and activities, as well as other programmes working on related topics or in neighbouring areas will be organised and stimulated throughout the project period. This is essential for conducting comparative analyses between communities in the oceanic areas and along the continental slopes and shelves. Chemosynthetic ecosystems are not included in Mar-Eco, partly because another proposed CoML pilot project, the ChEss, will focus specifically on such systems (see http://www.soc.soton.ac.uk/chess/). Other projects/programmes/agencies of particular interest are e.g. the CoML Gulf of Maine pilot project (http://www.whoi.edu/marinecensus/), the UK NERC Marine Productivity programme, ICES co-ordinated surveys (e.g. the redfish surveys in the
Irminger Sea) and working groups, international cetacean sightings, ICCAT co-ordinated monitoring of large pelagic fish such as tuna and swordfish, NOAA Office of Ocean Exploration, and InterRidge activities.

\subsection{Time frame and schedule}

The schedule and phases of MAR-ECO are the following:

Planning phase: 2001-2003

Field phase: 2003-2005

Analysis, synthesis: 2004-2008

Incorporation in OBIS: 2005-2008

The planning phase is scheduled to last 18 months, starting in November 2001. This phase will be followed by the field effort in 2003-2005. Incorporation in OBIS is scheduled to begin in 2005 and the completion of the project and a final synthesis for 2008. It is anticipated, however, that extensive material will be available for examination and detailed analyses also after the final year.

\section{Current status}

The status of Mar-Eco is that the planning phase has been initiated and a formal organisational structure has been established. A first planning workshop was held in Bremerhaven in January 2002 with the main objective of stimulating the network of experts to formulate component projects. Relevant funding agencies have been or will be alerted and the Steering Group will take steps to discuss the initiative with new potential contributors.

In Norway, a core group of scientists and engineers have been set up to assist the International Steering Group, and the project is now established within the IMR workplan. A special Public Outreach sub-group is developing an information and public outreach strategy, including web-based dissemination activity directed at schools and the general public. Contracts have been signed with several experts who will carry out data mining for the benefit of sub-groups writing component project proposals. Special efforts have been made to compile relevant bibliographies and these will be made available on the website www.mar-eco.no which functions as the main source of updates and background information. Also on this website are outlines of component projects being formulated, with information on principal investigators and prospective partners.

In June 2002, an "expression of interest" describing Mar-Eco was submitted to the European Union 6th Framework Programme in the hope that Mar-Eco will be accepted as an integrated project within that programme. Overall, however, the funding situation for the field and analyses phase remains uncertain, and proposals will have to be submitted to many national and international funding agencies, both public and private, in and after the planning phase. 
The Steering Group stimulates the formulation of component project proposals by organising and funding subgroup meetings and networking activity. The $\mathrm{SG}$ is assisted by appointed theme co-ordinators dealing with demersal nekton, pelagic nekton, zooplankton, and epibenthos projects. Several meetings have been held or are planned, and draft proposals are emerging. Some proposals have already been submitted to national funding agencies.

It is exceedingly difficult to produce a detailed timeline and implementation plan for the project given the continued uncertainty regarding funding, commitment of ship-time, and labour resources. A progress plan for the planning phase is followed, and includes a second major planning workshop to be held in January 2003. Several planning cruises have been and will be conducted to test equipment and methodology.

\section{Acknowledgements}

Thanks are due to the CoML staff and SSC, and to Jesse Ausubel of the Sloan Foundation for their efficient and enthusiastic support during the initiation process. We also thank all members of the Mar-Eco steering group for their great efforts during the development of the Science Plan and planning phase proposal, i.e. the documents on which this paper is based.

\section{References}

Angel, M.V., 1997. Pelagic biodiversity. In: Ormond, R.F.G., Gage, J.D., Angel, M.V. (Eds.), Marine Biodiversity: Patterns and Processes. Cambridge University Press, Cambridge, UK 449 p.

Ausubel, J.H., 1999. Toward a census of marine life. Oceanography 12, 4-5.

Berger, W.H., 1989. Global maps of ocean productivity. In: Berger, W.H., Smetacek, V.S., Wefer, G. (Eds.), Productivity of the Ocean: Present and Past. Wiley \& Sons, New York, pp. 429-455.

Bergstad, O.A., 2000. Patterns and processes of the ecosystems of the northern mid-Atlantic. A proposed Census of Marine Life initiative. Concept paper submitted to the Steering Committee of CoML, February 2001. Available on http://www.mar-eco.no/.

Bradley, D.L., 1999. Assessing the global distribution and abundance of marine organisms. Oceanography 12, 19-20.

Garrison, T., 1993. Oceanography: An Invitation to Marine Science. Wadsworth, Belmont, CA.

Grassle, J.F., 2000. The Ocean Biogeographic Information System (OBIS): an on-line, worldwide atlas for accessing, modeling and mapping marine biological data in a multidimensional geographic context. Oceanography 13, 5-7.
Hareide, N.-R., Skarboevik, E., Kjerstad, M., Shibanov, V., Vinnichenko, V., Gorchinsky, K., 1993. Forsoeksfiske etter orange roughy paa Den midt-atlantiske rygg med fabrikktraalaren m/t Ramoen, September 1-Oktober 8, 1993. Report, Moere Research, Aalesund, Norway and PINRO, Murmansk, Russia, 80 pp. + appendices (in Norwegian).

Hempel, G., 1968. Biologische Arbeiten auf den atlantischen Kuppenfahrten 1967 von F.S. Meteor. aturwiss. Rdsch. 21, 108-113.

Hempel, G., Nellen, W., 1972. Bericht über den Verlauf der RoßbreitenExpedition 1970. Meteor-Forsch.-Ergebnisse A 10, 51-78.

Iglesias, S., Muñoz, P.D., 2001. Spanish investigations on deep-sea resources in northern Mid-Atlantic Ridge and adjacent areas. Working Document presented to the Workshop on the CoML pilot project "Patterns and processes of the ecosystems of the northern MidAtlantic", Bergen, 12-13 February 2001, 7 p.

Kukuev, E.I., Karaseva, E.I., Feldman, V.N., 2000. On the mesopelagic ichthyofauna of the boreal zone of the northeastern. Atlantic. J. Ichthyol 40, 389-394.

Langedal, G., Hareide, N.-R., 1997. Rapport fra forsoeksfiske paa Reykjanesryggen/Midt-atlanterhavsryggen med M/S Skarheim juli 1997. Report, Norwegian Directorate of Fisheries and Moere Research, 58 p. (in Norwegian).

Magnusson, J.V., Magnusson, J., 1995. The distribution, relative abundance and the biology of the deep-sea fishes of the Icelandic slope and Reykjanes ridge. p. 161-200. In: Hopper, A.G. (Ed.), Deep-water Fisheries of the North-Atlantic Oceanic Slope. NATO ASI Series E. Appl. Sci. vol. 296420 p.

Merrett, N.R., Haedrich, R.L., 1997. Deep-sea Demersal Fish and Fisheries. Chapman \& Hall, London, 282 p.

OSPAR Commission, 2000. Quality Status Report 2000, Region V-Wider Atlantic. OSPAR Commission, London, $110 \mathrm{p}$.

Pfannkuche, O., Müller, T.J., Nellen W., Wefer, G., 2000. Ostatlantik 1998, Cruise No. 42, June 16-October 26, 1998. METEOR-Berichte, Universität Hamburg, 00-1, 259 p.

Randall, D.J., Farrell, A.P. (Eds.), 1997. Deep-sea Fishes. Fish Physiology, vol. 16. Academic Press, New York, 388 p.

Rogers, A.D., 1994. The biology of seamounts. Adv. Mar. Biol. 30, 306-350.

Santos, R.S., Hawkins, S., Monteiro, L.R., Alves, M., Isidro, E. J., 1995. Marine research, resources and conservation in the Azores. Aquatic Conservation: Mar. Freshw.Ecosyst. 5 (4), 311-354.

Thomsen, B., 1998. Faroese quest of orange roughy in the North Atlantic. ICES C.M. 1998/O:31.

Troyanovsky, F.M., Lisovsky, S.F., 1995. Russian (USSR) fisheries research in deep waters (below $500 \mathrm{~m}$ ) in the North Atlantic. p. 357-366. In: Hopper, A.G. (Ed.), Deep-water Fisheries of the North-Atlantic Oceanic Slope. NATO ASI Series, Series E. Appl. Sci., vol. 296. pp. 357-366 420 p.

Van Dover, C.L., 2000. The Ecology of Deep-Sea Hydrothermal Vents. Princeton University Press, Princeton, 424 p.

Vinnichenko, V.I., 1998. Alfonsino (Beryx splendens) biology and fishery on the seamounts in the open North Atlantic. ICES C.M. 1998/O:13, $13 \mathrm{p}$. 